\title{
Case of Complicated Fatty Liver of Pregnancy With Good Outcome
}

\author{
Mitra Eftekhariyazdi $^{\circledR}$, Behnaz Souizi $^{1}$, Manijeh Yousefi Moghaddam ${ }^{2}$, Forough Mortazavi $^{3 *}$
}

\begin{abstract}
Acute fatty liver of pregnancy (AFLP) is a rare condition with an incidence rate of 1 to 20000 that mostly occurs in the third trimester of pregnancy. There is no specific treatment for AFLP thus a conservative treatment is usually applied in this regard. This case report is related to a 28-year-old G3 P1 Ab1 L1 woman at 29 weeks of pregnancy who was referred to our emergency ward from a primary setting with an epigastric pain, a mild hypertension, and the suspicion of HELLP [Hemolysis, elevated liver enzymes, and low platelet count] syndrome. The lab exams ruled out viral infections including hepatitis B virus (HBV), hepatitis C virus (HCV), and Human immunodeficiency virus (HIV). In addition, the urine protein was $40 \mathrm{mg} / 600 \mathrm{cc}$. AFLP was diagnosed and a cesarean was performed under spinal analgesia because of elevated liver enzymes, proteinuria in the normal range for pregnancy, the presence of viral infections that involved the liver, and lack of pruritus. A 29-week girl with a weight of $1115 \mathrm{~g}$ was born and the patient was discharged with a good condition. At 5 days postpartum, she referred with abdominal pain, fever, as well as incisional redness and discharge. The ultrasound scan showed a hematoma in the depth of the subdermis point of the cesarean incision. Thus, antibiotics and one unit of fresh frozen plasma were infused. On 14-day postpartum, the patient was discharged with a good condition. The purpose of this study was to focus the attention of physicians to the point that AFLP may improve after childbirth but it may predispose the patient to coagulation disorders and hematoma.

Keywords: Pregnancy complications, Acute fatty liver, Gestational, therapy, Liver dysfunction, Postpartum
\end{abstract}

\section{Introduction}

Acute fatty liver of pregnancy (AFLP) appears in the third trimester of pregnancy mostly at 35-36 weeks (1) and rarely on immediate postpartum (2). It is a rare condition with the prevalence rate of $1 / 7000-1 / 20000$ (1-3) and a high perinatal mortality rate. Older women and primiparous, as well as those with low body mass index and multiple pregnancies are at the greatest risk of developing AFLP (1).

This fatal disease leads to liver insufficiency due to the fatty infiltration of hepatocytes. The usual symptoms of AFLP are jaundice, abdominal pain, nausea, vomiting, fever, and fatigue (4). In addition, acute renal failure, encephalopathy, gastrointestinal bleeding, pancreatitis, and coagulopathy may develop in severe cases. Pregnancy may terminate in stillbirth in up to $10 \%$ of the cases. Some babies are at the risk of developing life-threatening nonketotic hypoglycemia or dilated cardiomyopathy (5).

Diagnosis is based on clinical and paraclinical findings but the definite diagnosis is made by liver biopsy (6). AFLP must be differentiated with HELLP syndrome, pre-eclampsia, and acute viral hepatitis (7). Usually, liver tests and coagulopathy gradually become normal after delivery thus the termination of pregnancy is the first step to improve the prognosis (8). Early diagnosis, immediate delivery, and conservative care could improve maternal outcome whereas a delay in diagnosis may lead to hepatic failure, disseminated intravascular coagulation, encephalopathy, and death (7). The present study is a case report of a 28-year-old mother with AFLP who was managed with a conservative treatment. This case indicates that AFLP may develop earlier than expected in pregnancy. In addition, the development of a hematoma in the cesarean incision emphasizes that coagulative disorders may occur despite decreasing liver enzymes.

\section{Case Presentation}

A 28-year-old G3 P1 Ab1 L1 woman at 29 weeks of pregnancy was referred to the emergency ward of Mobini hospital affiliated to Sabzevar University of Medical Sciences on August 8, 2017, from a primary setting. The patient presented an epigastric pain that did not respond to medical therapy and a mild hypertension (first 130/70 then 150/80). She was suspected of developing HELLP syndrome which is defined as a condition of elevated liver enzyme levels, hemolysis, and low platelet levels (9). She mentioned a history of taking ranitidine due to gastric problems, as well as a history of hypertension in the first trimester of the pregnancy. The mode of her previous delivery was cesarean as well. The ultrasound scan on August sixth showed a 26-week fetus with breech presentation and normal amniotic fluid volume. 
Magnesium sulfate was started for the patient. Then, a consultation with an internist was done and lab exams ruled out the viral infections including $\mathrm{HBV}, \mathrm{HCV}$, and HIV. Therefore, the AFLP was diagnosed and a cesarean was performed under spinal analgesia due to elevated liver enzymes, normal-range proteinuria, and negative tests for viral hepatitis. Table 1 presents the changes in liver enzymes, platelet counts, bleeding time, bilirubin levels, fast blood sugar, creatinine, and white blood cell count from admission to the discharge of the patient. A severe attachment of the omentum to the uterus and the abdominal wall was detected and removed. Then, a 29-week girl with a weight of $1115 \mathrm{~g}$, Apgar score of 7-8, and clear amniotic fluid was born, followed by putting a drain inside the incision. On day one postpartum, a fluid regimen was begun, the drain was removed, and a consultation with a superior gastrointestinologist was performed for her abdominal pain. The ultrasound scan on August ninth indicated several stones in the gallbladder with a maximum of $15 \mathrm{~mm}$ diameter. On day two postpartum, the patient complained of a severe pain in her right lower quadrant of the abdomen which was relieved with an injection of $50 \mathrm{mg}$ pethidine. A usual regimen was started. On day three postpartum, a gradual decline was observed in the liver tests and the order of discharge was requested for the patient and she was recommended to be visited by a grand specialist in the gastrointestinal tract. On day four postpartum, she was discharged with a good condition although she came with abdominal pain, fever, along with incisional redness and discharge on day five postpartum. The ultrasound scan demonstrated a postpartum uterus with $65 \times 137 \mathrm{~mm}$. Myometrium echo in the anterior part was heterogenic. In the cesarean incision, a hypoechoic and heterogenic region was found with $23 \times 113 \mathrm{~mm}$ thickness in the subdermis depth indicating a hematoma. A little fluid was observed in the deeper part of the uterus in the anterior position with the extent to the serosal surface acetaminophen and cefazolin were started accordingly, followed by adding metronidazole and gentamicin on day six postpartum. On the next day, the patient was well with edema on the cesarean incision and had no anorexia, nausea, and vomiting. However, she had a fever at midnights. On day eight postpartum, a consultation with a surgeon was ordered because of mild fever on nights and the hematoma. The surgeon ordered a conservative control, an ultrasound scan, and a computerized tomographic (CT) scan. The ultrasound scan represented a linear subdermal collection of a localized fluid with $57 \times 10 \mathrm{~mm}$ diameters on the left side of the pubis. An image of a collection of pus with $58 \times 16$ $\mathrm{mm}$ diameter was observed in the depth of the suprapubic subdermal point under the incision of cesarean which seemed to have a connection with the previous collection, indicating a hematoma. One unit of fresh frozen plasma was infused and a spiral CT scan was performed on day nine postpartum. The liver and pancreas were normal and some stones were found in the gallbladder. One hematoma was confirmed in the depth of the lower anterior wall of the

Table 1. Laboratory Test Changes in Admission Period From Delivery Date to Day 12 Postpartum

\begin{tabular}{|c|c|c|c|c|c|c|c|c|c|c|}
\hline & \multirow{2}{*}{$\begin{array}{l}\text { Normal } \\
\text { value }^{\text {a }}(19)\end{array}$} & \multicolumn{5}{|l|}{ Admission } & \multicolumn{4}{|c|}{ Readmission } \\
\hline & & $\begin{array}{l}\text { Delivery } \\
\text { date ( } 8 \text { am) }\end{array}$ & $\begin{array}{l}\text { Delivery } \\
\text { data (23 pm) }\end{array}$ & Day 1 & Day 2 & Day 3 & Day 6 & Day 9 & Day 11 & Day 12 \\
\hline WBC count (Neutrophils) & $\begin{array}{l}5.6-16.9 \\
(50-75 \%)\end{array}$ & - & 10.7 & 15.3 & $\begin{array}{l}18.3 \\
(75 \%)\end{array}$ & $\begin{array}{l}20.7 \\
(80 \%)\end{array}$ & $\begin{array}{l}15.6 \\
(78 \%)\end{array}$ & $\begin{array}{l}13 \\
(76 \%)\end{array}$ & $\begin{array}{l}15.6 \\
(78 \%)\end{array}$ & $\begin{array}{l}13.1 \\
(80 \%)\end{array}$ \\
\hline $\mathrm{FBS}(\mathrm{mg} / \mathrm{dL})$ & $71-77$ & - & 60 & 81 & 58 & 55 & - & - & - & - \\
\hline $\mathrm{BUN}(\mathrm{mg} / \mathrm{dL})$ & 3-11 & 31 & 12 & 12 & 18 & 12 & 12.8 & - & 9 & 7.5 \\
\hline Creatinine (mg/dL) & 0.4-0.9 & 1.1 & 1.04 & 1 & 0.9 & 0.94 & 0.64 & 0.9 & 0.64 & 0.7 \\
\hline SGOT (U/L) & $4-32$ & 329 & 435 & 222 & 96 & 65 & 24 & - & - & 9 \\
\hline $\mathrm{SGPT}(\mathrm{U} / \mathrm{L})$ & $2-25$ & 230 & 450 & 207 & 127 & 96 & 20 & - & - & 7 \\
\hline ALP (U/L) & $38-229$ & - & - & 243 & 257 & 281 & - & - & - & 207 \\
\hline $\mathrm{LDH}(\mathrm{U} / \mathrm{L})$ & $82-524$ & 999 & 1320 & 779 & 625 & 577 & - & - & - & - \\
\hline $\mathrm{Hb}$ & $9.5-15$ & 12.4 & 12.7 & 10.5 & 10.5 & 11 & 10 & 9.3 & - & 9.3 \\
\hline PLT $\times 10^{9}$ & $146-429$ & 112 & 110 & 107 & 162 & 186 & 240 & 321 & 240 & 287 \\
\hline PTT (s) & $24-35$ & - & 30 & 35 & 41 & 35 & - & - & - & - \\
\hline PT (s) & $9.6-12.9$ & - & & 13 & 13 & 13 & - & - & - & - \\
\hline 24 h-Proteinuria (mg) & $\begin{array}{l}\text { Up to } 300 \\
\mathrm{mg} / \mathrm{L}\end{array}$ & $\begin{array}{l}40 \mathrm{mg} / 600 \\
\mathrm{cc}\end{array}$ & - & - & - & - & - & - & - & - \\
\hline Direct Bilirubin (mg/dL) & $0.1-0.5$ & 0.2 & - & 0.24 & 0.04 & 0.2 & 0.1 & 0.1 & 0.1 & 0.15 \\
\hline Total Bilirubin (mg/dL) & $0.1-1.1$ & 1.3 & - & 1.3 & 1.23 & 2.1 & 0.8 & 0.8 & 0.8 & 0.8 \\
\hline
\end{tabular}

Abbreviations: WBC, White blood cell count; FBS, fast blood sugar; BUN, Blood urea nitrogen; SGOT, serum glutamic-oxaloacetic transaminase; SGPT, serum glutamate-pyruvate transaminase; ALP, Alkaline phosphatase; LDH, Lactate dehydrogenase; Hb, Hemoglobin; PLT, Platele count; PTT, Partial thromboplastin time; PT, Protherombin time.

a In the third trimester.

Note: Bold figures are higher than the normal range. 
abdomen with diameters of $110 \times 40 \times 65 \mathrm{~mm}$ and little fluid was observed in the pelvis. The erythrocyte sedimentation rate and C-reactive protein were 95 and $3+$. On day 12 postpartum, the patient was well and the hematoma and the stiffness of the vulva demonstrated a decrease although she experienced low-grade fevers $(\mathrm{T}=38)$. Thus, intramuscular antibiotic therapy was stopped. On day 14 postpartum, she did not have a fever and was discharged. Tables 1 and 2 present data on laboratory tests and vital signs changes in the admission period from admission to day 14 postpartum. An informed consent was obtained from the patient for the publication of the present report.

\section{Discussion}

AFLP is a rare and fatal disease that usually occurs in late pregnancy. Accordingly, pregnancy termination is recommended because of the risk of hepatic failure. The diagnosis of AFLP is challenging because AFLP typically appears with unspecific signs and symptoms and the clinical features and laboratory tests resemble conditions such as acute viral hepatitis, preeclampsia, HELLP syndrome, and intrahepatic cholestasis (10).

The AFLP in our patient was diagnosed based on ruling out the mentioned conditions. Our patient did not show proteinuria normally observed in pre-eclampsia and HELLP syndrome. Furthermore, our patient had hypoglycemia which is not observed in HELLP syndrome (10). She did not have higher levels of serum transaminases (>1000 U/L), which is found in viral hepatitis (10) while she had negative viral tests. We ruled out intrahepatic cholestasis of pregnancy because our patient did not have jaundice and severe pruritus which is normally in intrahepatic cholestasis of pregnancy (10). Furthermore, several laboratory test results supported the diagnosis of AFLP. Our patients had an elevated white blood cell count, as well as elevated serum aspartate aminotransferase, alanine aminotransferase, and alkaline phosphatase which was associated with hypoglycemia. Thrombocytopenia was observed as well. The blood urea nitrogen and creatinine were also high and above the upper limit of the normal ranges respectively. The partial thromboplastin time (PTT) increased in the early postpartum.

Liver enzymes in AFLP usually decrease within 24-48 hours of delivery (11). The results of a study on 4377 deliveries detected 142 patients (3\% of deliveries) with abnormal liver tests with spontaneous recovery in the puerperium (12). However, hemostatic dysfunction may persist 4-5 days postpartum (13). In our patient, PTT increased and predisposed the mother to develop a hematoma despite declining the liver enzymes after the first day postpartum.

Women with AFLP usually receive conservative management in an intensive care unit because of the fatality of the condition (10,14-17). Therefore, the liver enzymes reduced after three days, but AFLP predisposed our patient to coagulation disorder and hematoma development which was cured with a conservative management. Considering that $70 \%$ of AFLP cases are developed in 34-36 weeks of pregnancy (1), our case is relatively unique. Our findings indicate that the diagnosis of AFLP may be complicated. In addition, it needs differentiation between some conditions such as HELLP syndrome, pregnancy elevated liver enzymes, and acute viral hepatitis (18).

The first limitation of the study is that the exact diagnosis of AFLP is only possible by liver biopsy which the present study failed to perform. Further, the cause of hematoma was determined based on the fact that the surgeon who performed cesarean was an experienced gynecologist.

\section{Conclusions}

In general, AFLP may develop in early days of the third trimester of pregnancy. Our findings revealed that women with AFLP may present the signs of improvement and a liver enzyme decline in the first day postpartum although a coagulation disorder may predispose the mother to develop a hematoma.

\section{Conflict of Interests}

The authors declare that they have no conflict of interests.

\section{Ethical Issues}

An informed consent was obtained from the patient for the publication of the present report.

\section{Financial Support}

No financial support received for this case-report.

\section{Acknowledgments}

The authors would like to thank the patient for her agreement regarding publishing this report.

\section{References}

1. Knight M, Nelson-Piercy C, Kurinczuk JJ, Spark P, Brocklehurst P. A prospective national study of acute fatty liver of pregnancy in the UK. Gut. 2008;57(7):951-956. doi:10.1136/gut.2008.148676

2. Al-Husban N, Al-Kuran O, Al Helou A. Postpartum acute fatty liver of pregnancy: a case report. J Med Case Rep. 2018;12(1):67. doi:10.1186/s13256-018-1593-3

3. Mjahed K, Charra B, Hamoudi D, Noun M, Barrou L. Acute fatty liver of pregnancy. Arch Gynecol Obstet. 2006;274(6):349-353. doi:10.1007/s00404-006-0203-6

4. Nelson D, Yost N, Cunningham F. Hemostatic dysfunction with acute fatty liver of pregnancy. Obstet Gynecol. 2014;124(1):40-46.

5. Lee RH, Tran TT. Acute fatty liver of pregnancy. UpToDate; 2018. Available from: https://www.uptodate.com/contents/ acute-fatty-liver-of-pregnancy.

6. Tran TT, Ahn J, Reau NS. ACG clinical guideline: liver disease and pregnancy. Am J Gastroenterol. 2016;111(2):176-194; quiz 196. doi:10.1038/ajg.2015.430

7. Liu J, Ghaziani TT, Wolf JL. Acute fatty liver disease 
of pregnancy: updates in pathogenesis, diagnosis, and management. Am J Gastroenterol. 2017;112(6):838-846. doi:10.1038/ajg.2017.54

8. Reau N, Bacq Y. The Liver in Pregnancy. In: Schiff ER, Maddrey WC, Sorrell MF, Reddy KR, eds. Schiff's Diseases of the Liver. 12th ed. Wiley-Blackwell; 2017:1232.

9. Corton MM, Leveno K, Bloom S, Spong CY, Cunnigham JD. Williams Obstetrics. 24th ed. New York: McGraw-Hill; 2010.

10. Ko H, Yoshida EM. Acute fatty liver of pregnancy. Can J Gastroenterol. 2006;20(1):25-30. doi:10.1155/2006/638131

11. Nelson DB, Yost NP, Cunningham FG. Acute fatty liver of pregnancy: clinical outcomes and expected duration of recovery. Am J Obstet Gynecol. 2013;209(5):456.e451-457. doi:10.1016/j.ajog.2013.07.006

12. Ch'ng CL, Morgan M, Hainsworth I, Kingham JG. Prospective study of liver dysfunction in pregnancy in Southwest Wales. Gut. 2002;51(6):876-880. doi:10.1136/ gut.51.6.876

13. Nelson DB, Yost NP, Cunningham FG. Hemostatic dysfunction with acute fatty liver of pregnancy. Obstet Gynecol. 2014;124(1):40-46. doi:10.1097/ aog.0000000000000296

14. Vora KS, Shah VR, Parikh GP. Acute fatty liver of pregnancy: a case report of an uncommon disease. Indian J Crit Care Med. 2009;13(1):34-36. doi:10.4103/0972-5229.53115

15. Vigil-de Gracia P, Montufar-Rueda C. Acute fatty liver of pregnancy: diagnosis, treatment, and outcome based on 35 consecutive cases. J Matern Fetal Neonatal Med. 2011;24(9):1143-1146. doi:10.3109/14767058.2010.531325

16. Yücesoy G, Ozkan SO, Bodur H, Cakiroğlu Y, Calişkan E, Ozeren S. Acute fatty liver of pregnancy complicated with disseminated intravascular coagulation and haemorrhage: a case report. Int J Clin Pract Suppl. 2005(147):82-84. doi:10.1111/j.1368-504x.2005.00371.x

17. Liu G, Shang X, Yuan B, Han C, Wang Y. Acute Fatty Liver of Pregnancy: Analysis on the Diagnosis and Treatment of 15 Cases. J Reprod Med. 2016;61(5-6):282-286.

18. Minakami H, Morikawa M, Yamada T, Yamada T, Akaishi R, Nishida R. Differentiation of acute fatty liver of pregnancy from syndrome of hemolysis, elevated liver enzymes and low platelet counts. J Obstet Gynaecol Res. 2014;40(3):641649. doi:10.1111/jog.12282

19. Abbassi-Ghanavati M, Greer LG, Cunningham FG. Pregnancy and laboratory studies: a reference table for clinicians. Obstet Gynecol. 2009;114(6):1326-1331. doi:10.1097/AOG.0b013e3181c2bde8

(c) 2020 The Author (s); This is an open-access article distributed under the terms of the Creative Commons Attribution License (http://creativecommons.org/licenses/by/4.0), which permits unrestricted use, distribution, and reproduction in any medium, provided the original work is properly cited. 